\title{
TERORISME DALAM BINGKAI MEDIA MASSA
}

\author{
(Analisis Framing 'Bangkit dari Teror' pada Program Acara \\ Talkshow Mata Najwa di Trans 7)
}

\author{
Dikhorir Afnan
}

Dosen Universitas Muhammadiyah Cirebon

Email:dikhorir@umc.ac.id

\begin{abstract}
ABSTRAK
Fenomena terorisme di Indonesia dalam satu dekade terakhir telah menyedot perhatian publik, baik nasional maupun internasional. Ada yang menyikapinya biasa-biasa saja, namun ada juga yang berasumsi berdasarkan perspektif politik, agama, sosial, maupun ideologi. Sebagai alat informasi yang strategis, media massa sangat mungkin mengonstruksi realitas di lapangan menjadi sebuah produk berita yang tidak hanya mempunyai nilai bisnis, tapi juga sarat dengan kepentingan ideologi media itu sendiri. Dalam konteks Ilmu Komunikasi, untuk menggambarkan proses penyeleksian dan penyorotan aspek-aspek khusus sebuah realita pada produk jurnalistik, analisis framing (pembingkaian) dapat mewakili tradisi yang mengedepankan pendekatan atau perspektif multidisipliner untuk menganalisis fenomena atau aktivitas komunikasi.
\end{abstract}

Kata Kunci: Terorisme, Framing, Media Massa

\section{ABSTRACT}

The phenomenon of terrorism in Indonesia in the past decade has attracted public attention, both nationally and internationally. There are those who react to it as usual, but some also assume based on political, religious, social and ideological perspectives. As a strategic information tool, mass media is very likely to construct reality on the ground into a news product that not only has business value, but is also loaded with the interests of the media ideology itself. In the context of Communication Science, to describe the process of selecting and highlighting specific aspects of reality in journalistic products, the analysis of framing (framing) can represent traditions that prioritize a multidisciplinary approach or perspective to analyze phenomena or communication activities.

Keywords: Terrorism, Framing, Mass Media 


\section{PENDAHULUAN}

Fenomena terorisme di Indonesia dalam dua dekade terakhir telah menyedot perhatian publik, baik nasional maupun internasional. Ada yang menyikapinya biasa-biasa saja, namun ada juga yang berasumsi berdasarkan perspektif politik, agama, sosial, maupun ideologi. Sebagai alat informasi yang strategis, media massa sangat mungkin mengonstruksi realitas di lapangan menjadi sebuah produk berita yang tidak hanya mempunyai nilai bisnis, tapi juga sarat dengan kepentingan ideologi media itu sendiri.

Dalam konteks Ilmu Komunikasi, untuk menggambarkan proses penyeleksian dan penyorotan aspek-aspek khusus sebuah realita pada produk jurnalistik, analisis framing (pembingkaian) dapat mewakili tradisi yang mengedepankan pendekatan atau perspektif multidisipliner untuk menganalisis fenomena atau aktivitas komunikasi.

Jika media massa sangat mungkin mengonstruksi realitas di lapangan menjadi sebuah produk berita yang tidak hanya mempunyai nilai bisnis, tapi juga sarat dengan kepentingan ideologi media itu sendiri, lalu pertanyaannya apakah mungkin media massa sangat "berkepentingan" dengan pemberitaan aksi-aksi terorisme? Atau sebaliknya, para pelaku teror memang sengaja melakukan aksinya secara terstruktur untuk menunjukkan eksistensi mereka sekaligus mencari perhatian publik melalui media massa?

Giessmann seperti dikutip Nunung Prajarto (dalam Jurnal Ilmu Sosial dan Ilmu Politik Vol 8, No.1 Juli 2014) berpendapat bahwa tidak menutup kemungkinan kelompok teroris mencari perhatian media massa sebagai saluran informasi yang strategis untuk mendapatkan penerimaan publik. Interdependensi kelompok teroris terhadap media massa bisa ditandai dengan tindakan-tindakan sensasional mereka untuk tujuan propaganda. Sedangkan bagi media massa, simbiosis dari aksi serangan teroris tidak lain adalah untuk mendapatkan angel-angel gambar yang menarik, eksklusif, dan tentunya bernilai bisnis.

Meski demikian, jauh lebih penting daripada itu, media massa mempunyai tanggung jawab yang besar atas setiap pemberitaan yang dimuat dan dipublikasi kepada khalayak luas. Bersandar pada kesadaran moral bagi seorang jurnalis adalah pilihan terbaik ketimbang melulu membangun opini yang justru malah 
menguntungkan bagi keberadaan para pelaku teror itu sendiri. Untuk mengetahui sejauh mana interdependensi para pelaku teror dengan pemberitaan di media massa, maka penulis merasa perlu untuk melakukan penelitian lebih lanjut terkait dengan terorisme dalam perspektif media massa. Secara sederhana, penelitian ini penulis beri judul "Terorisme dalam Bingkai Media Massa". Agar penelitian ini fokus pada substansi yang ingin diteliti, pendekatan teoretis yang dipilih adalah analisis framing pada program acara Mata Najwa edisi 23 Mei 2018 pukul 20.00 WIB di Trans 7 yang mengusung tema "Bangkit dari Teror".

\section{LANDASAN TEORETIS}

Secara etimologis, 'terorisme' berasal dari kata terrere (Latin), yang berarti 'menyebabkan (orang) gemetar'. Dengan demikian, terorisme dimaksudkan untuk membuat orang ketakutan. Sedangkan berdasarkan istilah, definisi 'terorisme' masih diperdebatkan oleh para ahli yang berkecimpung dalam masalah ini. Sebagai akibatnya, "tidak ada satu definisi yang diterima secara umum." Orang mempunyai pengertian yang berbedabeda tentang istilah terorisme dan cakupan dari artinya. Orang-orang yang terlibat di dalam perdebatan tersebut sering mencoba membuat definisi yang sesuai dengan keperluan dan kepentingan mereka. Dengan demikian, definisi terorisme yang diberikan pada umumnya merupakan refleksi dari kepentingan-kepentingan politik dan penilaian moral dari orangorang yang memberikan definisi (Diakses pada 23 Mei 2018 pukul 20.55 WIB dari Jurnal Refleksi: Vol 13, No.5 Oktober 2013 yang ditulis oleh Abdul Muis Naharong).

Referensi lain menyebutkan bahwa kata 'teror' (system, regime de terreur) muncul kali pertama pada tahun 1789 di dalam The Dictionnaire of The Academic Francaise (Marijan dalam Mubarak, Jurnal Studi Masyarakat Islam: Vol 15, No.2 Desember 2012). Konteks revolusi Prancis lekat di dalam penggunaan istilah itu. Karenanya, istilah terorisme pada waktu itu memiliki konotasi positif, yakni aksi-aksi yang dilakukan untuk menggulingkan penguasa yang lalim. Namun, literatur lain mencatat praktikpraktik terorisme sudah lama terjadi sejak sekitar 66-67 sebelum masehi, ketika kelompok ekstrem Yahudi melakukan aksi teror, termasuk di dalamnya pembunuhan terhadap bangsa Romawi yang melakukan pendudukan di wilayahnya. Sejak saat itu, aksi-aksi terorisme di berbagai belahan dunia yang melibatkan beragam etnik dan 
agama terus terjadi (Diakses pada 23 Mei 2018 pukul 20.53 WIB dari Jurnal Studi Masyarakat Islam: Vol 15, No.2 Desember 2012 yang ditulis oleh Zulfi Mubarak).

Sedangkan menurut Jainuri (dalam Mubarak, Jurnal Studi Masyarakat Islam: Vol 15, No.2 Desember 2012), istilah teror dan terorisme telah menjadi idiom ilmu sosial yang sangat popular pada dekade 1990-an dan awal 2000-an sebagai bentuk kekerasan agama. Tindakan teror telah muncul sepanjang sejarah umat manusia. Bagaimana putra Adam, Qabil meneror Habil karena dinilai menjadi penghambat keinginan Qabil. Beberapa bentuk teror telah menjadi cara yang umum untuk mengintimidasi lawan. Orang yang percaya bahwa dengan kekerasan dapat mengintimidasi musuh atau lawan agar takut. Sebagai sebuah label untuk tindakan kekerasan, istilah ini mencerminkan makna negatif bagi mereka yang dijuluki teroris. Dalam pengertian ini teroris disamakan dengan istilah menyakitkan lainnya dalam khazanah bahasa politik, seperti rasis, fasis, atau imperialis (Diakses pada 23 Mei 2018 pukul 20.53 WIB dari Jurnal Studi Masyarakat Islam: Vol 15, No.2 Desember 2012 yang ditulis oleh Zulfi Mubarak).

Lalu bagaimana media massa memainkan perannya untuk membingkai sebuah pemberitaan? Tentunya setiap dapur redaksi media massa memiliki cara pandang yang berbeda meskipun satu sama lain tengah mengupas satu isu yang sama kepada publik. Ada media massa yang memiliki karakter keras, begitu juga tidak sedikit media massa yang mempunyai tipikal yang lunak. Semua bergantung dari kebijakan yang diambil oleh pimpinan redaksi.

Tamburaka dalam Literasi Media: Cerdas Bermedia Khalayak Media Massa (2013:133) mengidentifikasi cara pemberitaan dan cara menyajikan isu dalam suatu berita, apabila suatu media cenderung tidak memiliki ketertarikan untuk mengangkat isu tersebut, maka akan dibelokkan. Misalkan dalam kasus hukum korupsi, media dapat mengangkat pemberitaan untuk melihat dari salah satu sudut pandang, apakah dari sudut ekonominya atau politik. Pemilihan sudut pandang tergantung dari para pembuat konten media. Jika memilih aspek ekonominya, maka narasumber dan fakta dari sudut pandang ekonomi. Demikian pula jika media cenderung menginginkan persoalan tersebut dilihat dari sudut pandang politik, maka fakta dan narasumbernya diambil dari para politikus. 
Media massa, kata Tamburaka, pada umumnya menggunakan framing (pembingkaian) untuk membelokkan masalah sebenarnya kepada persoalan lain sehingga berbeda maknanya. Maka teknik framing juga dapat digunakan oleh mereka yang tertarik menciptakan konten media. Tulisan, foto gambar yang dicari sendiri atau didapatkan dari pihak kedua sebelum disebarluaskan dapat disunting dan diedit untuk menghilangkan hal-hal yang tampak menimbulkan dampak negatif di masyarakat.

Volkmer (2016:493) dalam bukunya Encyclopedia of Communication Theory, yang diterjemahkan Tri Wibowo, menjelaskan bahwa teori framing bertujuan mengidentifikasi skemaskema yang digunakan individu memandang dunia. Akar teori framing sering dikaitkan dengan sosiolog Erving Goffman yang berpendapat bahwa desain interpretif merupakan elemen sentral dari sistem keyakinan kultural.

Goffman menyebut ini sebagai kerangka desain interpretif yang kita gunakan dalam pengalaman sehari-hari untuk memahami dunia. Frame atau "kerangka" membantu kita mereduksi kompleksitas informasi, namun ia bertindak dengan cara dua arah: frame membantu menginterpretasikan dan merekonstruksi realitas. Konsep frame Goffman memiliki akar konseptual dalam fenomenologi, pendekatan filsafat yang menyatakan bahwa makna dunia dipahami oleh individu berdasarkan keyakinan, pengalaman, dan pengetahuan dunia mereka.

Secara tradisional, makna dunia disampaikan melalui proses sosialisasi, menciptakan realitas kolektif di dalam suatu masyarakat atau kultur, sedangkan komunikasi dengan mediasi memberikan kerangka yang kuat untuk persepsi yang menentang dan merenegosiasikan pengalaman kehidupan ini.

Maka, menurut Volkmer, tidak mengejutkan jika teori framing menjadi penting bagi beberapa sektor dalam masyarakat media transnasional dewasa ini. Pengetahuan tentang teori framing adalah penting bagi perencanaan kampanye media dalam advertising, public relations, dan sektor politik. Teori framing, misalnya, digunakan oleh spin doctor untuk menyusun isu-isu politik dalam kampanye pemilu yang ditujukan bagi audiensi spesifik.

Akan tetapi, salah satu area penting dari teori framing adalah riset 
media dalam jurnalisme dan komunikasi politik. Setelah media menempati peran sebagai pilar keempat negara dalam masyarakat demokratis, periset media merasa teori framing berguna untuk menganalisis ketimpangan dan struktur kekuasaan yang memediasi isu-isu politik. Misalnya, kerangka suatu berita tentang lingkungan dapat berbeda dalam outlet media konservatif atau liberal. Akan tetapi, penggunaan teori framing tidak hanya untuk mengidentifikasi kerangka yang berbeda dari suatu cerita atau berita di banyak outlet berita, namun juga memungkinkan kita untuk mendeteksi bias jurnalistik. Penggunaan framing stereotip, frame gender, atau ketidakseimbangan representasi komunitas masyarakat yang relevan, seperti minoritas etnis di dalam suatu negara atau publik transnasional adalah contoh dari penggunaan kerangka yang berbeda-beda.

Selain proses penentuan-agenda, teori framing mempelajari skema yang berbeda di mana isu-isu diberitakan. Studi awal dalam riset framing mengidentifikasi kerangka utama dalam berita televisi: frame episodik-definisi frame kejadian tertentu-dan frame tematik, yang memosisikan isu dalam konteks diskursus publik yang lebih luas. Sarjana lainnya mengkaji kerangka yang digunakan dalam kampanye pemilu (Volkmer, 2016:494).

Singkatnya, teknik framing dalam pembuatan konten media sangat membantu bagi setiap orang yang ingin berpartisipasi secara mandiri dalam membuat konten media, di mana dia memiliki ide, gagasan yang sebenarnya penting namun belum diangkat oleh media mana pun. Dapat juga dengan cara mengendalikan suatu masalah dengan membingkai pesan dari sumber pertama dan mengolahnya, sehingga pesan itu menjadi lebih etis, sopan dan menarik, namun tidak menghilangkan nilai pentingnya. Jika merasa bahan baku informasi yang masih mentah itu berbau SARA, bisa terlebih dahulu diedit atau dihilangkan bahkan menambahkan teks atau gambar untuk mengarahkan suatu pesan agar lebih bermakna (Tamburaka, 2013).

\section{METODOLOGI PENELITIAN}

Penelitian ini menggunakan pendekatan kualitatif. Metode ini dimaksudkan agar peneliti mengerti dan mampu menginterpretasikan makna dari suatu teks dengan cara membingkai isu. Dalam perspektif komunikasi, analisis framing 
dipakai untuk membedah cara-cara atau ideologi media saat mengonstruksi fakta. Analisis ini mencermati strategi seleksi, penonjolan, dan pertautan fakta ke dalam berita agar lebih bermakna, lebih menarik, lebih berarti atau lebih diingat, untuk menggiring interpretasi khalayak sesuai perspektifnya. Dengan kata lain, framing adalah pendekatan untuk mengetahui bagaimana perspektif atau cara pandang yang digunakan oleh wartawan ketika menyeleksi isu dan menulis berita. Cara pandang atau perspektif itu pada akhirnya menentukan fakta apa yang diambil, bagian mana yang ditonjolkan dan dihilangkan, serta hendak dibawa ke mana berita tersebut (Nugroho, dkk dalam Sobur, 2012:162). Karenanya, berita menjadi manipulatif dan bertujuan mendominasi keberadaan subjek sebagai sesuatu yang legitimate, objektif, alamiah, wajar, atau tak terelakkan (Imawan dalam Sobur, 2012:162).

Belakangan, teori framing telah diperbaiki secara konseptual. Riset yang lebih baru mengkaji seperangkat frame spesifik, seperti frame seputar wacana elite karena banyak berita mendukung perspektif stakeholder yang berkuasa. Studi lainnya fokus pada frame konten yang mengidentifikasi cara-cara framing mendukung satu pihak dalam suatu perdebatan. Tipe riset framing lainnya mengkaji proses sosial dasar dari pembentukan framing.

Beberapa teoretis mereposisikan framing di dalam wilayah metodologi riset lain di komunikasi politik, dan berpendapat bahwa framing terdiri dari komponen makrolevel dan mikrolevel. Komponen level makro berkaitan dengan mode presentasi dan saling tumpang-tindih dengan penentuan agenda, sedangkan level mikro berhubungan dengan cara audiensi menggunakan informasi dan menentukan sikap terhadap isu tertentu yang bersinggungan dengan proses priming. "Priming" adalah cara media menawarkan konteks sebelumnya yang dengannya audiensi akan menginterpretasikan informasi selanjutnya, sehingga menciptakan kerangka referensi bagi audiensi (Volkmer, 2016:494).

\section{Rumusan Masalah}

Pertanyaan yang diajukan pada rumusan masalah ini adalah bagaimana Trans7 mengonstruksi realitas isu terorisme menjadi isu yang menarik dan bernilai? 


\section{Tujuan Penelitian}

Sedangkan tujuan penelitian ini adalah untuk mengetahui yang dilakukan Trans7 dalam mengonstruksi realitas isu terorisme menjadi sebuah isu yang menarik dan bernilai.

\section{PEMBAHASAN}

Mata Najwa adalah program gelar wicara yang dipandu oleh jurnalis senior, Najwa Shihab. Musim pertama disiarkan perdana di MetroTV sejak 25 November 2009, Mata Najwa konsisten menghadirkan topik-topik menarik dengan narasumber kelas satu. Talkshow ini ditayangkan setiap hari Rabu pukul 20.00 hingga 21.30 WIB. Sejumlah tamu istimewa telah hadir dan berbicara di Mata Najwa, di antaranya Presiden ke-3 RI, Bacharuddin Jusuf Habibie (episode: Habibie Hari Ini), Presiden ke-5 RI Megawati Soekarnoputri (episode: Apa Kata Mega?), Mantan Wakil Presiden Boediono (episode: Di Balik Diam Boediono), Wakil Presiden Jusuf Kalla (episode: Pemimpin Bernyali), Menteri BUMN Dahlan Iskan (episode: Komandan Koboi), dan Gubernur DKI Jakarta yang sekarang Presiden Indonesia, Joko Widodo (episode: Laga Ibukota)
(https://id.wikipedia.org/wiki/Mata_Najw Diakses pada Rabu 11 Juli 2018 pukul 22.58 WIB).

Mata Najwa resmi berakhir pada tanggal 23 Agustus 2017 dengan keputusan pemandu (tuan rumah) Mata Najwa untuk mengakhiri karier di MetroTV sekaligus sebagai tuan rumah Mata Najwa. Episode terakhir Mata Najwa di MetroTV adalah "Catatan Tanpa Titik" yang ditayangkan pada tanggal 30 Agustus 2017. Musim kedua Mata Najwa kembali tayang di Trans7 mulai 10 Januari 2018, dengan episode pertamanya berjudul "Indonesia Rumah Kita"

(https://id.wikipedia.org/wiki/Mata_Najw Diakses pada Rabu 11 Juli 2018 pukul 22.58 WIB).

Pada episode 23 Mei 2018 di waktu yang sama, Mata Najwa mengangkat isu terorisme yang kembali ramai diberitakan media massa pascaledakan bom di Gereja Santa Maria Tak Bercela Surabaya. Topik yang diangkat berjudul "Bangkit dari Teror". Menariknya, Najwa Shihab selaku tuan rumah pada program tersebut mempertemukan dua pihak, yakni mantan korban aksi terorisme dan mantan pelaku teror. Di antara para korban yang dihadirkan pada acara 
tersebut adalah Dwi Siti Rhomdoni dan Ipda Denny Mahieu, keduanya merupakan korban dari ledakan bom Thamrin Jakarta beberapa waktu lalu. Selain Dwi dan Ipda Denny, Najwa Shihab juga melakukan telekonference dengan salah satu keluarga korban ledakan bom di Gereja Santa Maria Tak Bercela, Monic Dewi Andini. Monic merupakan istri dari Bayu Rendra Wardana, korban tewas pada insiden yang terjadi pada Minggu, 13 Mei 2018 silam.

Dalam peristiwa yang mencekam tersebut, serangan bunuh diri para pelaku teror bom tersebut tidak hanya beraksi di Gereja Santa Maria Tak Bercela, tapi juga di dua gereja lainnya di Jawa Timur, yakni Gereja Kristen Indonesia Diponegoro dan Gereja Pantekosta Arjuna. Akibat aksi tak berprikemanusiaan tersebut, belasan orang dinyatakan meninggal dunia, termasuk Bayu Rendra Wardana yang pada saat kejadian berusaha menghalau pelaku teror bom yang menerobos masuk ke halaman Gereja Santa Maria Tak Bercela.

Adapun mantan pelaku teror bom yang ikut dihadirkan pada acara Mata Najwa episode "Bangkit dari Teror" tersebut antara lain; Yudi Zulfahri (mantan pengikut Aman Abdurrahman, salah satu teroris yang divonis hukuman mati), Sofyan Tsauri (mantan teroris yang beraksi di Aceh), dan Ibrahim Hasbi (mantan pemasok senjata untuk serangkaian aksi terorisme di Indonesia).

Jika diidentifikasi dari isu atau tema yang diangkat pada program tersebut, penulis berpendapat bahwa program Mata Najwa telah berhasil mengonstruksi sebuah realitas menjadi tayangan yang menarik untuk ditonton. Apalagi dengan dihadirkannya sejumlah narasumber yang relevan, semakin menguatkan jika program ini lebih mengedepankan aspek faktual dan aktual dan dapat dijadikan sebagai program tayangan alternatif yang sarat makna.

Lalu bagaimana Trans7 melalui program Mata Najwa ini melakukan penggiringan interpretasi kepada khalayak terkait isu terorisme? Pada tayangan edisi 23 Mei 2018, topik Mata Najwa yang diketengahkan kepada pemirsa menurut pandangan penulis sangat edukatif karena tim Mata Najwa mencoba mengarahkan pemahaman pemirsa terkait pentingnya makna perdamaian dan persatuan bangsa.

Upaya Najwa Shihab untuk melakukan penggiringan interpretasi tentang terorisme terutama menyangkut 
rasa kemanusiaan juga bisa

diidentifikasi manakala Najwa Shihab menanyakan adakah penyesalan terbesar yang dirasakan oleh para mantan pelaku teror atas sejumlah aksi yang dilakukannya?

"Ketika memutuskan untuk bergabung dengan kelompok pelaku teror dengan tugas masing-masing, apakah pernah terbersit dampak yang akan ditimbulkan?," tanya Najwa kepada ketiga mantan pelaku teror yang hadir dalam acara talkshow tersebut.

"Saat itu tidak ada yang kita pikirkan kecuali bagaimana kita punya rencana ini (pengeboman) agar berjalan lancar," jawab Yudi.

"Tujuan kita pada waktu itu adalah ingin mati syahid, dan tidak terpikir adanya korban. Saat itu, kami berpikir kalaupun mereka (para korban) tidak mati hari ini, toh mereka pada saatnya juga akan mati. Kami anggap semua ini adalah perjuangan. Kami seperti terpenjara oleh pikiran itu. Saya membaca beberapa surat Syekh Osama bin Laden ketika tim Navy Seal 7 menemukan beberapa surat. Isinya menyatakan bahwa kita tidak saja bertanggung jawab kepada Allah terhadap darah yang tumpah, tapi kita juga harus menanggung taswiyah (pencitraan/gambaran) Islam yang buruk. Inilah yang menyebabkan jihad kita tidak diterima oleh mayoritas umat Islam dikarenakan banyaknya jatuh korban di antara kaum muslimin itu sendiri. Di sini saya kaget, ternyata Al Qaeda (Syekh Osama bin Laden) itu mengevaluasi banyaknya jatuh korban teror yang membawa dampak luar biasa bagi para korban, dan tanggung jawabnya dikembalikan lagi kepada pelakunya. Ini membuat saya jadi takut, membunuh secara sengaja. Berarti ada kesalahan (atas perintah jihad) di sini, sehingga menimbulkan penyesalan yang mendalam bagi saya," timpal Sofyan Tsauri, mantan teroris yang beraksi di wilayah Aceh.

Dari uraian pembahasan di atas, maka dapat penulis deskripsikan bahwa framing pada program acara Mata Najwa yang mengangkat tema terorisme tersebut bisa saja dikategorikan sebagai sebuah rekonstruksi atas realitas yang mencoba dibangun oleh jurnalis Trans7 untuk mempelajari skema yang berbeda di mana isu-isu diberitakan. Sebagaimana paparan Volkmer tentang teori framing di mana pada studi awal riset framing adalah untuk mengidentifikasi kerangka utama dalam berita televisi: frame episodik-definisi frame kejadian tertentu-dan frame tematik, yang memosisikan isu dalam konteks diskursus publik yang lebih luas.

\section{SIMPULAN}

Adapun kesimpulan umum dari penelitian ini adalah teori framing menjadi penting di sejumlah sektor bagi masyarakat media kontemporer. Teori framing sebagaimana pandangan Volkmer, juga bisa digunakan oleh spin doctor untuk menyusun isu-isu politik 
dalam kampanye pemilu yang ditujukan bagi audiensi spesifik.

Penulis juga sependapat dengan pandangan Volkmer bahwa salah satu area penting dari teori framing adalah riset media dalam jurnalisme dan komunikasi politik. Setelah media menempati peran sebagai pilar keempat negara dalam masyarakat demokratis, periset media merasa teori framing berguna untuk menganalisis ketimpangan dan struktur kekuasaan yang memediasi isu-isu politik. Singkatnya bahwa Trans7 melalui program Mata Najwa episode 23 Mei 2018 telah berhasil mengonstruksi realitas isu terorisme menjadi sebuah isu yang menarik dan bermakna. Begitu juga dengan cara penggiringan interpretasi khalayak terkait isu terorisme telah mampu dikemas Mata Najwa menjadi sebuah isu yang lebih positif dan edukatif.

\section{DAFTAR PUSTAKA}

Dewi, Irra Chrisyanti. 2015. Pengantar Psikologi Media. Jakarta: Prestasi Pustakaraya

Sobur, Alex. 2012. Analisis Teks Media: Suatu Pengantar untuk Analisis Wacana, Analisis Semiotik, dan Analisis Framing. Bandung: Remaja Rosdakarya
Volkmer, Ingrid. 2016. Ensiklopedia Teori Komunikasi. Diterjemahkan dari Buku Asli Encyclopedia of Communication Theory, SAGE Publication, Inc. Penerjemah Tri Wibowo. Jakarta: Kencana

Tamburaka, Apriadi. 2013. Literasi Media: Cerdas Bermedia Khalayak Media Massa. Jakarta: Rajawali Pers

\section{Jurnal:}

Mubarak, Zulfi. 2012. Jurnal Studi Masyarakat Islam: Vol 15, No.2 Desember 2012

Naharong, Abdul Muis. 2013. Jurnal Refleksi: Vol 13, No.5 Oktober 2013

Prajarto, Nunung. 2014. Jurnal Ilmu Sosial dan Ilmu Politik Vol 8, No.1 Juli 2014 